\title{
Клинико-лабораторные и биохимические аспекты диагностики кардиоваскулярных осложнений у детей и подростков с ожирением
}

( Ю Ю.Г. Самойлова ${ }^{1}$, О.А. Олейник ${ }^{1}$, Е.В. Саган ${ }^{1}$, Н.С. Денисов ${ }^{1 *}$

${ }^{1}$ Сибирский государственный медицинский университет, кафредра детских болезней 634050, г. Томск, Московский тракт 2

*Email: denisov.ssmu@gmail.com

Цель исследования - установить вклад клинико-лабораторных и метаболических фракторов риска развития кардиоваскулярных нарушений в формировании персонифрицированного подхода диагностики при ожирении у детей и подростков. Определение состава кишечной микробиоты производилось по методу Осипова, гормональные исследования осуществлялись методом ИФА. По результатам работы у детей с ожирением выявлено увеличение концентрации инсулина, триацилглицеролов и лептина, снижение концентрации ТМАО, инкретинов, глюкагона и резистина, в тонком кишечнике увеличена общая бактериальная и вирусная нагрузка, снижено видовое разнообразие, в микробиоте толстого кишечника отмечено снижение количества резидентной микрофрлоры.

Ключевые слова: ожирение, кишечная микробиота, триметиламиноксид, глюкагоноподобный пептид.

Ожирение у детей и подростков в последнее время является одной из актуальных проблем современного здравоохранения. В развитых странах ожирение достигло уровня эпидемии и наблюдается прогрессирующий рост распространенности таких хронических заболеваний как сахарный диабет, сердечно-сосудистые заболевания и некоторые формы рака [1].

Независимые исследования установили, что именно в детском и подростковом возрасте фрормируются основные фракторы развития кардиоваскулярной патологии, реализация которых ухудшает прогноз заболевания, снижает качество жизни и социальную адаптацию. Ошибочным было мнение, что детей и подростков стоит относить к группе низкого риска развития сердечно-сосудистых заболеваний.

До сих пор не установлены единые биохимические и гормональные маркеры поражения кардиоваскулярной системы в педиатрической практике у детей и подростков с избыточным накоплением жировой ткани. Данный фракт делает необходимым выявить фракторы сердечно-сосудистого риска у детей и подростков с избыточной массой тела [2].

В последние годы активно рассматривается кишечная микробиота как один из главных фракторов, способствующих развитию ожирения. Исследования показали, что микробиота кишечника, регулируя массу тела, энергетический гомеостаз и процессы воспаления, играет важную роль в патофизиологии ожирения. Физиологические функции микробиоты распространяются намного дальше кишечника, оказывая влияние как на печень, так и на головной мозг и жировую ткань [3]. 
Жировая ткань является источником таких биологически активных молекул (адипокинов) как лептин и резистин, обладающих как системным, так и местным действием. Изменение концентрации данных адипокинов связывают с прогрессированием ожирения, с развитием инсулинорезистентности, дисфункции эндотелия и повышением артериального давления. Изучение биологически активных молекул жировой ткани позволяет по-новому оценить патогенез ожирения и связанных с ним сердечнососудистых заболеваний и сахарного диабета 2 типа [4]

Превращение поступивших нутриентов, содержащих триметиламин, микробиотой является новым путем атерогенеза. В результате каскада биохимических реакций образуется проатерогенный маркер - триметиламин-N-оксида. В 2011 году была выявлена связь между ТМАО и риском сердечно-сосудистых катастрофр $[5,6]$.

Таким образом, актуальной задачей для современной медицины является разработка простых, неинвазивных и доступных методов диагностики ожирения и ассоциированных с ним сердечно-сосудистых осложнений. Решение этой задачи позволит еще на потенциально обратимой стадии проводить профилактические и лечебные мероприятия и улучшить прогноз основного заболевания, а также качество и продолжительность жизни пациента.

Цель исследования. Установить вклад клинико-лабораторных и метаболических фракторов риска развития кардиоваскулярных нарушений в формировании персонифицированного подхода диагностики при ожирении у детей и подростков. Задачи: 1. Изучить клинико-лабораторные и метаболические показатели у детей и подростков с избыточной массой тела и ожирением. 2. Исследовать уровень маркёров кардиоваскулярных рисков (триметиламиноксид, показатели липидного спектра) и состав кишечной микробиоты у детей и подростков с избыточной массой тела и ожирением. 3. Оценить гормональную активность жировой ткани у детей и подростков с избыточной массой тела и ожирением.

Материал и методы. Настоящее исследование выполнено на базе ФГБОУ ВО СибГМУ Минздрава России. В качестве клинической базы использована ОГАУЗ «Детская больница №1». Подготовка и исследование образцов микробиоты кишечника проводились на базе Томского Политехнического Университета (научный парк ТПУ) и на базе Лаборатории Микробной Хроматографии (г. Санкт-Петербург). Биохимический и иммуноферментный анализы проводились на базе Центральной научно-исследовательской лаборатории ФГБОУ ВО СибГМУ Минздрава России (заведующий д-р мед наук, профессор Е.В. Удут) и на кафедре биохимии и молекулярной биологии с курсом клинической лабораторной диагностики ФГБОУ ВО СибГМУ Минздрава России. В соответствии с поставленными задачами сформированы 2 группы детей и подростков. Основную группу составили 35 детей с избыточной массой тела и ожирением определенной в зависимости от SDS ИМТ согласно действующей классификации ВОЗ в возрасте 10-14 лет. Критерии включения: возраст от 10 до 15 лет, избыточный вес или ожирение, подписанное информационное согласие на участие в исследовании. Критерии исключения: наличие клинически значимых неконтролируемых состояний или заболеваний, которые, по мнению исследователя, могут повлиять на участие пациента в исследовании и/или проведении каких-либо процедур и интерпретации результатов в рамках исследования; отказ от участия в исследовании.

Контрольную группу составили 10 детей сопоставимых по полу и возрасту. Критерии включения: нормальная масса тела, подписанное информационное согласие на участие в исследовании. Критерии исключения: наличие клинически значимых неконтролируемых состояний или заболеваний, которые, по мнению исследователя, могут повлиять на участие пациента в исследовании и/или проведении каких-либо процедур и интерпретации результатов в рамках исследования; отказ от участия в исследовании. 
Определение состава кишечной микробиоты проводилось по методу Осипова при помощи газовой хроматографии-масс спектрометрии. Материалом для исследования служила сыворотка крови. Для определения уровня глюкозы и липидного спектра использовался автоматический биохимический анализатор ARCHITECT с8000. Определение концентрации ТМАО, лептина, иризина, резистина проводилось с использованием наборов компании Cloud-Clone Corp., методом твердофазного иммуноферментного анализа.

Результаты. Обследованы 45 подростков, результаты биохимического и гормонального исследований представлены в таблице 1. Исследование липидного спектра показало статистически значимое увеличение уровня триацилглицеридов - $1,1(0,8 ; 1,7)$ ммоль/л в опытной группе по сравнению с контрольной - 0,9 $(0,7 ; 1,0)$ ммоль/л.

Таблица 1. Основные биохимические и гормональные показатели.

\begin{tabular}{|c|c|c|c|}
\hline & $\begin{array}{c}\text { Основная группа } \\
\text { n=35 } \\
\text { Me (Q1:Q3) }\end{array}$ & $\begin{array}{c}\text { Контроль } \\
n=10 \\
\text { Me (Q1:Q3) }\end{array}$ & $\mathrm{p}$ \\
\hline Возраст & $12,1(10,8 ; 14,6)$ & $13,1(10,5 ; 13,8)$ & 0,499 \\
\hline $\mathrm{Bec}$ & $75,9(63,6 ; 97,8)$ & $45,0(32,0 ; 55,2)$ & $<0,001^{*}$ \\
\hline Рост & $1,6(1,49 ; 1,69)$ & $1,5(1,4 ; 1,6)$ & 0,115 \\
\hline ИMТ & $30(27,3 ; 34,9)$ & $18,7(16,4 ; 20,9)$ & $<0,001^{*}$ \\
\hline SDS ИMT & $2,9(2,4 ; 3,4)$ & $(-0,1(-0,6 ; 0,5)$ & $<0,001^{*}$ \\
\hline \% избытка & $43,5(27,1 ; 59,2)$ & $0(0 ; 0)$ & $<0,001^{\star}$ \\
\hline GLP-2, пг/мл & $102,95(91,97 ; 149,15)$ & $\begin{array}{c}506,1(385,5 \\
698,7)\end{array}$ & $<0,001^{*}$ \\
\hline GLP-1, пг/мл & $20(17,3 ; 24,0)$ & $29,6(24,9 ; 33,0)$ & $<0,001^{*}$ \\
\hline Инсулин, мкЕд/мЛ & $16,1(10,2 ; 33,5)$ & $5,7(5,1 ; 7,9)$ & $0,001^{*}$ \\
\hline С-пептид, нг/мл & $1,8(0,2 ; 2,6)$ & $3,1(1,6 ; 3,7)$ & $0,021^{*}$ \\
\hline Глюкагон, пг/мл & $174,3(156,2 ; 200,1)$ & $\begin{array}{c}223,9(210,3 ; \\
271,9)\end{array}$ & $<0,001^{*}$ \\
\hline TMAO, пг/мл & $265,4(198,7 ; 374,0)$ & $\begin{array}{c}786,3(618,6 \\
1242,8)\end{array}$ & $<0,001^{*}$ \\
\hline Глюкоза, ммоль/л & $4,9(4,3 ; 5,2)$ & $5,1(4,1 ; 5,3)$ & 0,71 \\
\hline Ирисин, пг/мЛ & $7,2(6,9 ; 7,7)$ & $7,3(7,1 ; 7,5)$ & 0,71 \\
\hline Лептин пг/мл & $4,5(2,2 ; 23,7)$ & $19,0(12,5 ; 25,7)$ & $0,008^{*}$ \\
\hline
\end{tabular}




\begin{tabular}{|l|c|c|c|} 
Резистин нг/мл & $8,8(7,3 ; 26,7)$ & $25,1(24,4 ; 25,7)$ & $\mathbf{0 , 0 1 9 ^ { * }}$ \\
\hline $\begin{array}{l}\text { Общий холестерол, } \\
\text { ммоль/л }\end{array}$ & $4,4(3,9 ; 5,0)$ & $4,8(3,9 ; 5,3)$ & 0,415 \\
\hline ЛПВП, ммоль/л & $1,1(0,9 ; 1,6)$ & $1,0(0,9 ; 1,2)$ & 0,326 \\
\hline ЛПНП, ммоль/л & $2,9(2,3 ; 3,4)$ & $3,0(2,2 ; 3,5)$ & 0,989 \\
\hline ЛПОНП, ммоль/л & $0,9(0,49 ; 1,34)$ & $0,6(0,5 ; 0,8)$ & 0,07 \\
\hline $\begin{array}{l}\text { Индекс атероген- } \\
\text { ности }\end{array}$ & $2,65(1,98 ; 3,45)$ & $2,9(2,7 ; 3,1)$ & 0,572 \\
\hline $\begin{array}{l}\text { Триацилглицериды, } \\
\text { ммоль/л }\end{array}$ & $1,1(0,8 ; 1,7)$ & $0,9(0,7 ; 1,0)$ & $\mathbf{0 , 0 4 4}$ \\
\hline
\end{tabular}

Примечание: *-различия статистически значимы при уровне $p<0,0$

В таблице 2 обозначены различия в составе микробиоты тонкого кишечника. В опытной группе отмечено повышение общей бактериальной нагрузки - 19146 (14549; 25514) кл/г*105 в опытной и $12278,5(10783,5 ; 14087)$ кл/г*105 в контрольной. Отмечено повышение нагрузки резидентной микрофрлоры - $19146(14549 ; 25456)$ кл/г*105 в опытной и $12241(10783,5 ; 14087)$ кл/г¹05 в контрольной группе.

Таблица 2. Основные представители микробиоты кишечника биотопа «тонкая кишка» у детей с избыточной массой тела и ожирением, по сравнению со здоровыми детьми

\begin{tabular}{|c|c|c|c|}
\hline $\begin{array}{l}\text { Основные } \\
\text { представители }\end{array}$ & $\begin{array}{c}\text { Дети с избыточ- } \\
\text { ной массой тела } \\
\text { и ожирением } \\
\text { n=35 } \\
\text { Me (Q1:Q3) }\end{array}$ & $\begin{array}{c}\text { Дети с нормаль- } \\
\text { ной массой тела } \\
\qquad \mathrm{n}=10 \\
\text { Me (Q1:Q3) }\end{array}$ & $\begin{array}{l}\text { p- } \\
\text { коэфффициент } \\
\text { достоверно- } \\
\text { сти }\end{array}$ \\
\hline $\begin{array}{l}\text { Общая бактериальная } \\
\text { нагрузка }\left(\text { кл/ז*10 } 10^{5)}\right.\end{array}$ & $\begin{array}{l}19146(14549 \\
25514)\end{array}$ & $\begin{array}{c}12278,5(10783,5 \\
14087)\end{array}$ & $<0,001^{*}$ \\
\hline $\begin{array}{l}\text { Резидентные- } \quad \text { нагрузка } \\
(\text { кл/г*10 }\end{array}$ & $\begin{array}{l}19146(14549 ; \\
25456)\end{array}$ & $\begin{array}{c}12241(10783,5 \\
14087)\end{array}$ & $<0,001^{*}$ \\
\hline Резидентные от ОБН (\%) & $100(100 ; 100)$ & $100(100 ; 100)$ & 0,638 \\
\hline $\begin{array}{l}\text { Транзиторные- } \quad \text { нагрузка } \\
(\text { кл/г¹0 }\end{array}$ & $0(0 ; 0)$ & $0(0 ; 0)$ & 0,861 \\
\hline Транзиторные от ОБН (\%) & $0(0 ; 0)$ & $0(0 ; 0)$ & 0,638 \\
\hline
\end{tabular}




\begin{tabular}{|l|c|c|c|} 
Анаэробные бактерии- & $17548(13158 ;$ & $11661,5(10027,3 ;$ & $0,001^{*}$ \\
нагрузка $\left(\right.$ кл/ $/ \Gamma^{*} 10^{5)}$ & $22881)$ & $13386)$ & \\
\hline
\end{tabular}

\begin{tabular}{|c|c|c|c|}
\hline $\begin{array}{c}\text { Анаэробные бактерии-от } \\
\text { ОБН (\%) }\end{array}$ & $92(90 ; 95)$ & $95(93,3 ; 95,3)$ & 0,131 \\
\hline 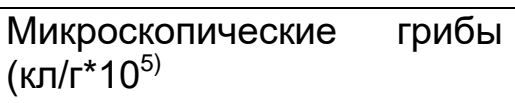 & 2878 (1433; 4423) & $\begin{array}{l}3838(2919,5 \\
5934,3)\end{array}$ & 0,093 \\
\hline Вирусы (кл/г*105) & 3879 (2410; 16200) & $854,5(653,8 ; 1178)$ & $<0,001^{*}$ \\
\hline
\end{tabular}

Примечание: *-различия статистически значимы при уровне $p<0,05$

В таблице 3 показаны различия в составе микробиоты толстого кишечника. Показано снижение общей бактериальной нагрузки - $32457(24319,5 ; 52388)$ кл/г*10 $10^{5}$ в опытной и $59766,5(48804,8 ; 78909)$ кл/ $\Gamma^{*} 10^{5}$ в контрольной группах. Также снижена нагрузки резидентной микрофрлоры с 59625 (47887; 78909) кл/г*105 в контрольной до $32223(23981,5$; $52373,5)$ кл/г*105 в опытной группе.

Таблица 3. Характеристика основных представителей микробиоты кишечника биотопа «просветная микробиота толстой кишки» у детей с избыточной массой тела и ожирением, по сравнению со здоровыми детьми

\begin{tabular}{|c|c|c|c|}
\hline $\begin{array}{l}\text { Наименование основных } \\
\text { представителей микро- } \\
\text { биоты кишечника }\end{array}$ & $\begin{array}{c}\text { Дети с избы- } \\
\text { точной массой } \\
\text { тела и ожире- } \\
\text { нием } \\
\text { n=35 } \\
\text { Me (Q1:Q3) }\end{array}$ & $\begin{array}{c}\text { Дети с нормаль- } \\
\text { ной массой тела } \\
\text { n=10 } \\
\text { Me (Q1:Q3) }\end{array}$ & $\begin{array}{l}\text { р-коэфффициент } \\
\text { достоверности }\end{array}$ \\
\hline 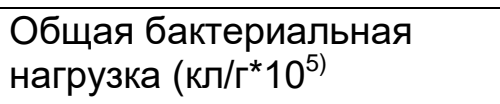 & $\begin{array}{c}32457(24319,5 \\
52388)\end{array}$ & $\begin{array}{c}59766,5(48804,8 \\
78909)\end{array}$ & 0,01 \\
\hline $\begin{array}{l}\text { Резидентные- нагрузка } \\
\left(\text { кл/ז } 10^{5)}\right.\end{array}$ & $\begin{array}{c}32223(23981,5 \\
52373,5)\end{array}$ & $\begin{array}{c}59625(47887 \\
78909)\end{array}$ & 0,01 \\
\hline Резидентные от ОБН (\%) & $100(99 ; 100)$ & $100(99 ; 100)$ & 0,546 \\
\hline $\begin{array}{l}\text { Транзиторные- нагрузка } \\
\left(\kappa л / \Gamma^{*} 10^{5)}\right.\end{array}$ & $120(0 ; 364)$ & $221,5(0 ; 260,3)$ & 0,884 \\
\hline Транзиторные от ОБН (\%) & $0(0 ; 1)$ & $0(0 ; 1)$ & 0,546 \\
\hline 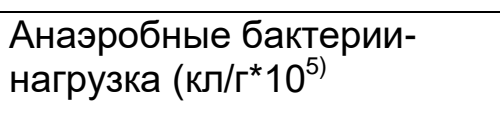 & $\begin{array}{l}30078(22007 \\
47278,5)\end{array}$ & $\begin{array}{c}57245,5(43431,3 \\
76447,3)\end{array}$ & 0,009 \\
\hline Анаэробные бактерии-от & $91(87 ; 93)$ & $95,5(94 ; 97)$ & 0,002 \\
\hline
\end{tabular}




\begin{tabular}{|c|c|c|c|}
\hline ОБН (\%) & & & \\
\hline $\begin{array}{l}\text { Микроскопические грибы } \\
\left(\kappa л / \check{\digamma}^{*} 10^{5)}\right.\end{array}$ & $\begin{array}{c}6143(2148,5 \\
15355)\end{array}$ & $\begin{array}{c}51180,5(40447,5 \\
141306,3)\end{array}$ & $<0,001$ \\
\hline Вирусы (кл/г*105) & $0(0 ; 0)$ & $0(0 ; 437,8)$ & 0,546 \\
\hline
\end{tabular}

Примечание: *-различия статистически значимы при уровне $p<0,05$

Результаты гормональных исследований представлены в таблице 4.

Таблица 4. Результаты гормонального исследования.

\begin{tabular}{|l|l|l|}
\hline Гормон & $\begin{array}{l}\text { Основная группа } \\
(\mathrm{n}=10) \\
\mathrm{Me}(\mathrm{Q} 1: \mathrm{Q} 3)\end{array}$ & $\begin{array}{l}\text { Контрольная группа } \\
(\mathrm{n}=20) \\
\mathrm{Me}(\mathrm{Q} 1: \mathrm{Q} 3)\end{array}$ \\
\hline GLP-1 пг/мл & $20(18,0 ; 24,4)$ & $31,1(24,5 ; 36,1)$ * \\
\hline GLP-2 пг/мл & $106,1(90,3 ; 163,7)$ & $736,7(464,8 ; 881,2)$ * \\
\hline Иризин нг/мл & $7,3(7,1 ; 7,5)$ & $7,2(6,9 ; 7,7)$ \\
\hline Инсулин мкЕд/мл & $16,1(10,2 ; 33,5)$ & $5,7(5,1 ; 7,9)$ * \\
\hline Глюкагон пг/мл & $174,3(156,2 ; 200,1)$ & $223,9(210,3 ; 271,9)$ * \\
\hline Резистин пг/мл & $25,1(24,4 ; 25,7)$ & $8,8(7,3 ; 9,7)$ * \\
\hline Лептин пг/мл & $19,0(12,5 ; 25,7)$ & $4,5(2,2 ; 5,7)$ * \\
\hline ТМАО пг/мл & $254,2(198,7 ; 377,0)$ & $893,3(729,9 ; 1218,0)$ * \\
\hline
\end{tabular}

Примечание: *- $p<0,05$.

Уровень GLP- 1 был ниже в основной группе и составлял 20 пг/мл $(18,0 ; 24,4)$, в контрольной группе - 31,1 пг/мл $(24,5 ; 36,1)$, p=0,001, GLP- 2 в основной группе 106,1 пг/мл (90,3; 163,7), в контрольной группе 736,7 пг/мл (464,8; 881,2), p <0,001.

При этом уровень ТМАО у детей с ожирением оказался статистически значимо ниже $254,2(198,7 ; 377,0)$ пг/мл, чем в контрольной группе - 893,3 $(729,9 ; 1218,0)$ пг/мл.

Уровень лептина статистически значимо повышен в основной группе $19,0(12,5 ; 25,7)$ пг/мл по сравнению с контрольной - 4,5 (2,2; 5,7) пг/мл.

Уровень резистина статистически значимо выше в основной группе - $25,1(24,4 ; 25,7)$ пг/мл, чем в контрольной - 8,8 (7,3; 9,7) пг/мл. 
Уровень инсулина статистически значимо повышен в основной группе - 16,1 (10,2; $33,5)$ мкЕд/мл по сравнению с контрольной группой - 5,7 $(5,1 ; 7,9)$ мкЕд/мл.

Уровень глюкагона статистически значимо снизился в опытной группе - 174,3 (156,2; $200,1)$ пг/мл по сравнению с контрольной - $\quad 223,9(210,3 ; 271,9)$ пг/мл.

Уровень иризина статистически значимо не изменился - $7,3(7,1 ; 7,5)$ пг/мл в основной группе, $7,2(6,9 ; 7,7)$ пг/мл в контрольной.

Выводы. 1. Выявлено увеличение концентрации инсулина $(p=0,001)$ у детей и подростков с избыточной массой тела и ожирением 1-2 степени. 2. У детей и подростков с избыточной массой тела и ожирением 1-2 степени отмечается снижение концентрации TMAO, повышение триацилглицеролов, в тонком кишечнике увеличена общая бактериальная нагрузка, снижено видовое разнообразие (преобладал род Firmicutes), повышена вирусная нагрузка (Эпштейна-Барр, простой герпес), в микробиоте толстого кишечника отмечено снижение количества резидентной микрофрлоры. 3. Обнаружен умеренный инкретиновый дефицит (снижение концентрации ГПП-1 и ГПП-2), снижение содержания глюкагона и резистина, повышение концентрации лептина.

\section{Литература}

1. Ожирение: современный взгляд на проблему [Text] / А.О. Разина, Е.Е. Ачкасов, С.Д. Руненко // Ожирение и метаболизм. — 2015. — Vol. 13, № 1. - P. 3-8.

2. Диагностика, лечение и профилактика ожирения у детей [Текст] / А. И.л // Смоленский медицинский альманах. - 2016. - № 3. - С. 184-191.

3. Alteration of the gut microbiota associated with childhood obesity by 16S rRNA gene sequencing [Text] / X. Chen, H. Sun, F. Jiang, Y. Shen, X. Li, X. Hu, X. Shen, P. Wei // PeerJ. - 2020. - Vol. 8. - P. e8317.

4. Adipose Tissue and Adipokines: The Association with and Application of Adipokines in Obesity [Электронный ресурс] - Режим доступа: https://www.hindawi.com/journals/scientifica/2014/328592/ (дата обращения: 26.05.2021).

5. Implication of Trimethylamine $\mathrm{N}$-Oxide (TMAO) in Disease: Potential Biomarker or New Therapeutic Target [Текст] / M.H. Janeiro, M.J. Ramírez, F.I. Milagro, J.A. Martínez, M. Solas // Nutrients. - 2018. - T. 10, № 10.

6. Trimethylamine and Trimethylamine N-Oxide, a Flavin-Containing Monooxygenase 3 (FMO3)-Mediated Host-Microbiome Metabolic Axis Implicated in Health and Disease [Text] / D. Fennema, I.R. Phillips, E.A. Shephard // Drug Metabolism and Disposition. - 2016. Vol. 44, № 11. - P. 1839-1850. 


\title{
Clinical, laboratory and biochemical aspects of the diagnosis of cardiovascular com-
} plications in obese children and adolescents

\author{
Y.G. Samoilova ${ }^{1}$, O.A. Oleinik ${ }^{1}$, E.V. Sagan ${ }^{1}$, N.S. Denisov ${ }^{1}$ * \\ ${ }^{1}$ Siberian State Medical University, Department of Childhood Diseases \\ 634050, Tomsk, Moscow tract 2 \\ *Email:denisov.ssmu@gmail.com
}

The aim of the study is to establish the contribution of clinical, laboratory and metabolic risk factors for the development of cardiovascular formations of a personalized approach to diagnostics in obesity in children and adolescents. Determination of the composition of the intestinal microbiota was carried out according to the Osipov method, hormonal studies were carried out by the ELISA method. According to the results of work in obese children, an increase in the concentration of insulin, triacylglycerols and leptin, a decrease in the concentration of TMAO, incretins, glucagon and resistin, in the small intestine, the total bacterial and viral load is increased, the species diversity is reduced, and a decrease in the microbiota of the large intestine is noted. the amount of resident microflora.

Key words: obesity, intestinal microbiota, trimethylamine oxide, glucagon-like peptide. 